\title{
LITERARY TEACHING AND ITS CONSTRAINTS: PARADIGMS AND PROBLEMS
}

\author{
Ali Mustofa \\ English Department, Surabaya State University \\ Email: ali_mustofa2012@yahoo.co.id
}

APA Citation: Mustofa, A. (2016). Literary teaching and its constrains: Paradigms and problems. English Review, 4(2), 219-230

Received: 12-02-2016

Accepted: 19-03-2016

Published: 01-06-2016

\begin{abstract}
The paper will explore the nature of the literary teaching and its constraints. In language teaching, literary teaching has been promoted influential and approved effective to encourage the students' character building in terms of some issues: historical, philosophical, cultural, social, and psychological contexts. Historically, literary teaching will provide students and learners of the ancients' way of life and learn from the best in the past for their life experience. Some constraints may arise in language teaching due to the cultural and the philosophical boundaries. The constraints may be put into some categories; philosophical, cultural, social, and psychological. To generalize the idea, literary teaching needs efforts to boost the students' skills to creatively launch themselves to a higher level of thinking order to achieve the goals of literary teaching and the demand of curriculum.

Keywords: literary teaching, humanity issues, constraints, critical thinking, competency
\end{abstract}

\section{INTRODUCTION}

There are many studies which confront literary teaching. To mention a few there are Khatib, Rezaei, and Derakhshan (2011), Yeasmen, Azad, and Ferdoush (2011), Mujumdar (2010), Cruz (2010), Yueh Wu (2008), Abdullah, Zakaria, Ismail, Mansor and Aziz (2007), Buttler (2006), Hismanoglu (2005), Saviddou (2004), Mc Kay (1982), and de Riverol (1991). They have contested the teaching of English and literature into a package which will generate the issues on developing the new method in language teaching. To them, literature is an object to be observed as a medium of learning a language. Besides, they also found out that teaching a language through literature will also generate another advantages for both teacher and students. Most of them suggested that literature is an interested resource to bridge the gap of students' language problems with their language proficiency. Khatib, Rezaei, and Derakhshan (2011) have completed their findings that, “... literature is a promising tool for language learning purposes". At the same time they have cited some important figures who have recalled the return of literature into language teaching such as Carter \& Burton (1982), Maley \& Moulding (1985), Brumfit \& Carter (1986), Collie \& Slater (1987), Carter, Walker, Brumfit (1989), Carter \& Long (1991), and also Bassnet \& Grundy (1993). They have been recalled to resurrect the function of literature in language teaching after being neglected for some period of times in 70s to 80s language teaching curriculum. Yeasmen, Azad, and Ferdoush (2011) focused on designing appropriate classroom activities using literary work to ease students' anxiety in developing their 
language competency in classroom setting. They asserted that teaching language using literary text through appropriate classroom tasks is an effective way to teach EFL learners. Mujumdar (2010) also found out that teaching literature in language teaching curriculum can also elevate the students' learning demand of ideal language performance. Mujumdar also suggested that the teacher of literature should have a complex skill and knowledge of the language being communicated in the teaching of literature. It includes the linguistic and non linguistic skills as well as literary horizons. Mujumdar's findings are not far different to what has been generated by Cruz (2010) and Yueh Wu (2008). Cruz (2010) has studied that literature will also enrich students' knowledge of linguistics elements and culture of the language being studied. It also enriches the students' understanding on how to interact with other people from different culture and learn their ways of life, beliefs, values and attitudes. Meanwhile, Yueh $\mathrm{Wu}$ said that the use of multiple teaching techniques in the teaching of literature will make the students feel interested in studying literary work and hence their language performance will also increase significantly.

Other researchers such as Abdullah, Zakaria, Ismail, Mansor and Aziz (2007), Buttler (2006), Hismanoglu (2005), Saviddou (2004), Mc Kay (1982), and de Riverol (1991) have more or less the same ideas, that using literature in language learning classrooms will provide better atmosphere in language teaching and learning. Their ideas have sought a response that teaching language using literary work as a tool to elevate the students' understanding of the elements of language and culture being studied is approved effective and interesting. However there are some constraints which those researchers did not pay much attention to, in which in the teaching of language and literature some issues of difficulties may arise and distract the objective of language and literature learning. It is because these two entities are different in some matters. The paper will seek to evaluate the problems in literary teaching. It overviews the paradigms and problems which are usually taken into consideration by literary teachers and language practitioners. Therefore, it firstly discusses the in-between language and literary teaching. Secondly, it exposes the constraints or problems in literary teaching, and the proposed solutions are also suggested as well.

\section{METHOD}

The paper overviewed the constraints of the literary teaching, in a more specific ways, while at the same time it also tried to give solutions over the problems faced by teachers and curriculum developers. The method used to discuss the problems is problem solving discussion by which the data were cross checked and reviewed eclectically from different sources and opinions. The results of the discussion were validated and evaluated by using the previous studies and research of the same topics.

\section{RESULTS AND DISCUSSION The In-Between Language and Literary Teaching}

It is widely known that in language teaching, the process of acquiring new knowledge of language being studied is gained through the practices and the skills to apply the rule of language construction. Every day use of the studied language will foster the acquisition of the language. It is, then, generating the ideas of language 
ENGLISH REVIEW: Journal of English Education Vol. 4, Issue 2, June 2016

teaching methodologies which state that language is acquired through series of practice. It is quite different with what is called as literary acquisition. Literary acquisition is nothing more than literary experience. The ability to understand literary sense is nonetheless an intuition. Therefore, there is no any fixed method in literary teaching.

Since it is an intuition which plays an important role in it, the series of practices are directed to understand the elements and values of the works being studied. The students are introduced to the concepts and theories of literary works' principles, and they are suggested to write what they have in minds about the works they have read and understood. Khatib, Rezaei, and Derakhshan (2011) note that eventhough literary works cannot provide direct needs of courses in EAP or ESP, it can be considered as, “... a caralyst for quickening language learning process".

The role of literature in language teaching has been admitted crucial and influential. It is shown by the government's concern in this field by launching the curricular support to it seriously. One of the Singapore's governments' projects in this response is of Literature in English Teaching Syllabus 2013: Lower and Upper Secondary. The syllabus grabs the ideas of literary teaching and its methodological problems. One of the statements of the book says that

"Literature also builds in students socio-cultural sensitivity and awareness, as well as a global outlook, by offering opportunities for them to explore a wide range of literary texts written in different contexts and from various parts of the world, connecting them to other ages and cultures. It develops
ISSN 2301-7554

https://journal.uniku.ac.id/index.php/ERJEE

empathy and stimulates thinking about beliefs and values" (2013:2) It means that it has been realized the function of literature in educational place is influential, and it also determines the development of sensitivity and awareness of the students in global contexts. It is because most of literary works discuss about global issues. This is in line with what has been perpetuated by Van (2009), Tayebipour (2009), and Maley (1989a) as cited by Khatib, Rezaei and Derakhsan (2011) that literature offers universal concepts so that it promotes cultural and intercultural sensitivity and awareness. By understanding those issues in literature, it can further add students' understanding of the whole wide world. When the above demand is compared to the objectives of literary teaching, the following objectives will give other insights into the nature of literary teaching:

- Discover the joys of reading literature and become aware of new ways perceiving and world around them;

- Appreciate the aesthetic value of language;

- Engage personality with a variety of texts and draw connections between self, texts and the world in order to develop intellectual, emotional, socio-cultural and global awareness;

- Articulate perceptive and analytical thinking when discussing and writing about literary texts;

- Explore how the elements of different genres function in literary works to achieve specific effects; and

- Appreciate the importance of the contexts in which literary texts are written and understood (2013:6).

Looking at the above objectives, it is an urge to promote literary teaching in schools and universities in order to make 
the students of both institutions to be more aware of global issues contextually. It is because literature also offers cultural and contextual issues. However, it should be taken into consideration that according to Maley (1989a) that literary teaching should also be put together with the demand of language teaching. He proposes language-based model which concerns literature for language development and awareness purpose. Though, Maley's model of literary teaching is not much well applicable to literary teaching, but his suggestion is an example of models in literary teaching which was adopted several years ago included in teaching model for language learning methodology.

An approach which lends itself well to the range of strategies used in language teaching common approach to literature in the EFL classroom is what Carter and Long (1991) refer to as the 'language-based approach'. Such an approach enables learners to access a text in a systematic and careful way in order to demonstrate specific linguistic characteristics e.g. literal and figurative language-cloze procedure, guess exercises, mixed up sentences, summary writing, creative writing and role playwhich all form part of the selection of EFL and activities used by teachers to deconstruct literary texts in order to provide specific linguistic goals. McRae (1996) describes this model as taking a 'reductive' approach to literature. These activities are disconnected from the literary goals of the specific text in that they can be applied to any text. There is little engagement of the learner with the text other than for purely linguistic practice; literature is used in a rather pointless and mechanistic way in order to present for a series of language activities motored by the teacher.
What has been suggested by Long \& Carter (1991) and McRae (1996) as well, is only to help the language learners and teachers in evaluating the texts (literary works) in order to make them engage well in making use of language for teaching purpose. Literary work is used purposeless. It is only used as a cultural site to be discussed for certain other objective. As a matter of fact, literary teaching should achieve the goal to teach the concepts and primary means of literary aspects. It must go through some methodological investigations to grab a certain and complex ideas on how to make it sociable to students. The point is to make the students become more aware and more sensitive toward issues of humanity. It should be accompanied by the appropriate use of language instruction, so that the students will grab the whole idea of the teaching learning process. To make use of literary work for other purpose of other than to investigate the contents of it is only to make fun of it. The students only get what is to be communicated rather than to discern the insights of it.

\section{The Constraints in Literary Teaching: Historical, Philosophical, Cultural and Social, and Psychological Contexts When discussing about literary teaching, it is not without some constraints. There are some problems which arise related to the teaching of literature as follows: historical, philosophical, psychological, and social problems. However, those matters can be accommodated and re-evaluated by the teachers and curriculum designers to ease the problems of literary teaching practically and methodologically.}


ENGLISH REVIEW: Journal of English Education Vol. 4, Issue 2, June 2016
ISSN 2301-7554

https://journal.uniku.ac.id/index.php/ERJEE

\section{Historical Context}

Historical background refers to the social and historical contexts in which a certain work of literature was produced. It also includes relevant facts of the author's life and works. Therefore, historical background of English literature is quite vague and broad. However, in order to provide an example, Beowulf in the 8th century, which was considered as the greatest Old English poem of about 3200 lines, the first English epic, whose author is unknown, is an interesting example. It is composed of lined verses which tell a story. The story is about Hrothgar, King of the Danes, and Beowulf, a brave young man from Sweden, who goes to help the king. The poem provides an interesting picture of life in those days and also of speech (since Old English is of course a foreign language). English, as known before, descends from the language spoken by the North Germanic tribes who settled in England from the 5th century A.D onwards. They had no writing system (except runes, used as charms) until they learned the Latin alphabet from Roman invaders.

The earliest written works in Old English (as their language is now known to scholars) were probably composed orally at first, and may have been passed on from speaker to speaker before being written. Old English literature is mostly chronicle and poetry-lyric, descriptive but chiefly narrative or epic. By the time, literacy becomes wide-spread, Old English is effectively a foreign and dead language. And its forms do not significantly affect subsequent developments in English literature. By the way, from this kind of history, students learn where and when the language develops, who spoke the language, and who wrote the language, and how the language developed after some period of time.

The problems often arise when the students are asked to understand literary work which uses old version of language, old English version for an example. They seem to be frustrated in understanding the elements of the work because they do not have any idea of the words or sentences they must encounter. However, the students learn how to understand the language carefully in order to grab the sense of the work. It means that the students will be exposed to complex difficult problems. They have to understand the ingredients of the work, and at the same time they have to understand the language. By this, they will learn of the development of language use historically. The role of the teachers in this way is crucial and important. He/she should be able to explain the problem of the language use in the work which encountered some changes both historical and cultural. The teacher should function himself/herself as literary specialist as well as a linguistic expert.

\section{Philosophical Context}

Philosophically, students are supposed to learn humanity essence through the philosophical teachings inside literary works they read. As a philosophical site of life, literary works provide ample of moral teachings and values as well. "Literary theory" is the body of ideas and methods used in the practical reading of literature. By literary theory, it is referred not to the meaning of a work of literature but to the theories that reveal what literature can mean. Literary theory is a description of the underlying principles, one might say the tools, by which one attempts to understand literature. All literary 
interpretation draws on a basis in theory but can serve as a justification for very different kinds of critical activity.

It is literary theory that formulates the relationship between author and work; literary theory develops the significance of race, class, and gender for literary study, both from the standpoint of the biography of the author and an analysis of their thematic presence within texts. Literary theory offers varying approaches for understanding the role of historical context in interpretation as well as the relevance of linguistic and unconscious elements of the text. The problem which often arises is that students do not really understand literary theory as an influential part to understand the body of a literary work. Literary theory is a philosophical foundation for students to understand the work well. How can a student understand the problem of Christianity problems in a work of literature when they did not ever read the explanation of Christian religion before? In this matter, teachers should be able to bridge the gaps of students' need to understand some conceptual features of literary works and some theoretical frameworks which can be used to evaluate the works. By this sense, teachers should be able to function themselves to be theorists who are really expert in conceptualizing the features of the works and relate them with the issues outside the works.

The philosophical constraints may be considered as the most complex problems compared to the other problems. They include other aspects of competences for both language learners and their teachers. They also incorporate some methodological problems and conceptual features which must be put forward by the teachers before starting the classes. The preparation should be made in order to make the classes run well. Another thing is that the teacher should take a look at the syllabus as well as the curricular guidance before executing the conceptual frameworks in literary studies to be understood by students.

\section{Cultural and Social Contexts}

The word "culture", in one hand, is used because it implies the integrated structures of human behavior that incorporates thoughts, communications, actions, customs, beliefs, values, and institutions of racial, ethnic, religious, or social groups. The word "competence", on the other hand, is used because it suggests having the capacity to role in a specific way: the capacity to function within the context of culturally integrated patterns of human behavior defined by a group. Being competent in cross-cultural functioning means learning new patterns of behavior and effectively applying them in the appropriate settings (Thomas, 1981). Being culturally competent means having the capacity to function effectively in other cultural contexts. Cultural studies concerns itself with the meaning and practices of everyday life. Cultural practices comprise the ways people do particular things (such as watching television, or eating out) in a given culture. Particular meanings attach to the ways people in particular cultures do things. When considering cultural competence; a concise, practical definition, and some explanation of relevant ideas are needed. Cross, Bazron, Dennis, \& Isaacs (1989) explored the concept of cultural competence in the system of care, and developed the definition and framework used here. They are appropriately applied in the school-based programs. Cultural competence is defined as a set 
of congruent behaviors, attitudes, and policies that come together in a system, agency, or among professionals and enables that system, agency, or those professionals to work effectively in cross-cultural situations (Cross et al., 1989; Isaacs \& Benjamin, 1991). Operationally defined, cultural competence is the integration and transformation of knowledge about individuals and groups of people into specific standards, policies, practices, and attitudes used in appropriate cultural settings to increase the quality of services; thereby producing better outcomes.

It is important, however, to make the students understand of the cultural and social contexts of literary works they read on. Cultural and social contexts will bridge them to really aware of issues in time and space when the works were produced. They could easily relate those issues toward the contemporary problems in their own time. To understand the practices, beliefs, values, laws, policies and standards inside the works of literature, will give them chances to figure out the contextual issues which then enable them to give response and to give respect of others' cultural issues. It is the reason why a literary teacher should be able to acknowledge the values and systems of different cultural contexts in works of literature with the ones in his own time, as well as his students' time, in order to enable the students to think more clearly of cultural and social contexts.

\section{Psychological Context}

Psychologically, students are to be exposed to the contextual teaching materials which make them feel secure to access humanity problems in the works, while at the same time they also learn how to give response to psychological problems the characters in the works have. In literary analysis, psychological approach contends that literary characters behave according to the same psychological consistencies and probabilities as real people, and that the motives for their behavior can be discovered and a psychological evaluation derived from the text itself. This frame of reference is concerned primarily with behavior, either or a character or an author, as it is symbolically reflected in the literary work.

Literary works provide access to think and to behave psychologically, especially when the students must react against the idea that contradicts their common beliefs. In the meantime, students often find difficult to understand the psychological problems the characters in the works have. It is sometimes because the teachers have seldom given them access to learn how to act and to give response psychologically. Sharing and discussing over a certain case in the class, is an example to train students to think and to react over something psychologically.

That there are similarities between what is done in language arts and in science or other subject is not so surprising. But it occurs that one might also draw a parallel conclusion between teaching any academic subject and teaching morality. It is widely accepted that, in order for young people to learn to be good people, they should be shown how to act. Teachers, in particular time and chance, try to set an example by the way they treat others over a certain case. And, indeed, some studies suggest that children or young people are more likely to imitate if they have watched someone else does so. Part of the problem is that modelling is a concept rooted in behaviorism. It began as a refinement of 
the principles of operant and classical conditioning. Those principles could not account for the fact that people sometimes learn from what they have observed, acting in ways for which they themselves received no reinforcement. But modelling, like reinforcing, is just another technique for getting someone to behave in a particular way; it does not necessarily promote a dedication to, or an understanding of, that behavior (Meyers, 1986).

\section{Literary Teaching Methodology}

By making use of those real life contexts, the accessible social and psychological affairs, the students are prepared to explore their very nature of communicating the ideas of humanity. It means that they are also prepared to have and to understand philosophical, psychological, and social skills. Simultaneously, the students are also equipped with the competencies in language skills; their ability to develop their oral skills to defend their critical thinking argumentatively, their positive and critical judgement which are manifested in their argumentative writing skills, their active involvement in sharing and understanding of a discussion over the subject matters the teacher and the students have in class, and attentively listen to any kind of problematic issues which are generated from the materials they share among their own peers.

Thoughtful assignments can be designed specifically to encourage a sharper, more active response to authors. It is possible to dispense with the tired practice of asking students whether they agree or disagree with what they have read. Teachers of course want to teach by doing so valuable to students. It may make sense not only to use explanation as a separate strategy alongside modelling, but to combine the two approaches into what might be called "deep modelling." Here, it does not only set an example for students but try to make it clear to them what the teacher is doing and why he is doing it.

Verbalizing is a familiar strategy to many of teachers that is intended to help students comprehend more of what they read.

Exactly the same thing happens when students encounter a series of finished products, whether they are books, scientific laws, or ethical precepts. Thus, one solution is to allow them to watch something being written, or proved, or decided, in order to make the activity in question more accessible and less intimidating. Watching movies together with their teacher and friends may also add up to the conclusion over this discussion. To watch the finished product such as a movie is an interesting experience for students to react over some matters contextually.

\section{Reliability of the Students' Evaluation}

In literary teaching, the teachers are suggested to apply democratic assessment practices because it will involve the teacher and the students to act out together to evaluate their learning process. Any time that students are involved in evaluating performance, whether their own or that of their classmates, the validity and reliability of their assessment is called into question. This kind of fear should not be accommodated. Without guidance, students have a distorted view of their performance (Oscarson 2009; Zakian, Moradan, \& Naghibi, 2012). The same research shows that with practice, training, and regular feedback from their teacher, the students' assessment of their performance agreed with that of their teacher. 
Involvement in a democratic process of assessment allows students to gain knowledge, experience, and understanding of how to judge oral and written expression. Through dialog, the students and teacher can negotiate the meaning of the objectives stated in the curriculum or mandated by the curriculum designer. For assignments that challenge students to create with language, whether orally or through written composition, the teacher and students can collaborate in creating a rubric or checklist that outlines what will be assessed. Feedback from the teacher after each performance will help students understand whether or not they have mastered the skill or concept.

Allowing students a voice in the assessment process compels them to analyze their own performance. Through analyzing their performance, students sharpen up critical thinking skills and develop autonomy (Tully, 2009). In time, students regard themselves as knowledgeable, and rightly so, which empowers them to be competent, independent learners. Allowing students a voice in the assessment process compels them to listen to their classmates (Iberri-Shea, 2009). An honest teacher will acknowledge that there are many styles of speaking or of writing for which he and his students may hold opposite, but equally valid opinions. By giving the students the opportunities to freely express their opinion about issues such as how a paper looks or how their classmate's gestures distracted the audience from the message, and by valuing those opinions, the teacher models the democratic process of respecting other's opinions. This respect empowers students to find their voice and to fearlessly use it.

In doing so, students are expected to have their own evaluation. It means that the class should carry out a peer assessment. With this, the students are given a free chance to develop and express their own ideas about peer evaluation. Peer evaluation offers a mutual and beneficial supervision both students and teachers to gain an objective result of an evaluation. Teachers can adopt this kind of assessment with respect to students' point of view over other's weakness and strengths in mastering a skill. In a classroom presentation carried out by a group of students discussing a topic, for example, can promote peer-assessment. The rest of the students will give their own judgment toward the problems risen in the discussion. This will promote a democratic nuance since other students will give witness to others' competence and performance. Teachers' feedback should be delivered in the end of the presentation, either in appraisal or criticism, in order to exhibit the openness of the value and judgment.

However, curiosity and resourcefulness are not the only casualties of this kind of teaching; students' inclination to object, to resist, to refuse to be cowed by authority is also affected. The teacher should reject a focus on right answers and conventional methods, in other words, not only because it promotes shallow learning but because it promotes passive acceptance. These are the model of assessment which can be used in measuring the students' learning outcome. The following models of assessments are strongly suggested to encourage the students to attend the classes creatively and critically, and involve in a democratic assessment in every part of the project; they are projects, open-ended response questions, performance based, portfolios, quiz or pop quiz, end of chapter or unit test, and mid or final term test. Basically, those 
forms of tests are commonly acknowledged and generally applied by language teachers in schools and universities. However, the form and model of tests are of course chosen in accordance with the need of the assessment for each of the learning outcome the teachers wish to obtain.

Project based task, first and foremost, can be done individually or in a group. By giving a student a project and a length of time in order to do it, a teacher can assess how the student organizes time, generates problems, and solves those problems. By doing the project in a group, the teacher can also assess how students interact with others and how they participate in group settings. In order for the project to be a success in terms of assessing the student, the teacher must give clear instructions and deadlines.

Open-ended response questions, secondly, involves the teacher or evaluator asking the student a question and the student giving the answer orally or by writing it down. This is an excellent way to evaluate the student's critical thinking process. Performancebased type of assessment requires students to perform actions such as answering questions or doing specific activities. The most common way to do this is to ask students how they came up with the answers to a question and asking them to explain their thought processes orally or by writing short essays. Thirdly, a portfolio is an excellent way to assess a student's progress. The teacher will collect examples of the student's work over a period of time, and place it in a file. Sometimes a school has a portfolio of the student's work that spans several years. The teacher can have a look through the portfolio to see if the student is improving, staying the same, or regressing. This is also an excellent way to show the parents how their children are doing in school. During a conference, a teacher can simply pull the students portfolios with the proof of what they have or have not been doing in class.

Fourth type of test is quiz or pop quiz. This assessment is usually done in the middle of a unit to see how students are doing with the material. A pop quiz is an excellent way to see if students paid attention in class that day or read the materials assigned to them. Fifth, end of chapter/unit test, it is the test which teachers mostly use in their assessment. This usually involves a multiple choice, short answer, essay, true/false, fill in the blank or matching test to show how much the students learned from the materials that were just covered in the class. Finally, mid or final term test in which it is the common used test in schools or universities in order to measure the students' progress during their length of time to study in a period of time. The test is given either in the middle way of lesson or in the end of the lesson. Mid and final tests are given to state whether the students can go up to the next level of study or not.

\section{CONCLUSION}

Literature is a source of authentic material, which conveys the use of linguistics by those who have mastered it. It contains an aesthetic representation of the spoken language, which enriches students' language and culture unconsciously. Culture, on the one hand, offers an interdisciplinary field that includes artistic discourses, social conventions, and reflexive impacts. It open doors for students to increase their knowledge of the target culture as they can contemplate and critically comment on people's way of life, values, attitudes, 
ENGLISH REVIEW: Journal of English Education Vol. 4, Issue 2, June 2016
ISSN 2301-7554

https://journal.uniku.ac.id/index.php/ERJEE and beliefs, standards, laws, religions and regard how these elements manifest into some different categories and forms in it.

It is true then that literature provides a motivating drive for language learning and teaching due to its spectacular features not readily found in any other texts. Therefore, some methodological issues on literary teaching have been perpetuated and promoted in the field of language and literature teaching in EFL/ESL's scopes. This will also generate some issues of some practical classroom techniques. However, with respect to the teaching and learning methodology over literary teaching, there must be some constraints that the students, the teachers, and syllabus designers must aware of.

There are some problems they have to encounter not to overcome them but to work on them so that the teaching and learning process become more bearable. The constraints are mentioned earlier in the discussions: historical problems, which are more closely related to the historical background of literary work that the students must understand in order to discern the structure of the society and the cultural context in which the work was produced. Philosophical constraints involve the difficulty of the students to master the conceptual framework to understand the work. It is because the students are of course lack of some information on literary theories so that they find some complicated issues which they cannot grab in mind. Cultural and social problems are mainly on the situation and context of cultural awareness the students must encounter when understanding a work of literature. This problem may produce another difficulty for the students that they could not imagine the condition of the social culture in the work they read. It is because there is a gap between their cultural knowledge with what had been intended by the author of the social and cultural condition of a certain society in a work. The last problem is a psychological context. It challenges the students to think and give response over a certain psychological phenomena in the work they are reading. The students often find difficulty to investigate the psychological problems in the work they encounter.

Those constraints may arise some mechanisms to act against them in response to develop some methods in literary teaching. The teachers are suggested to develop their critical views and orientations when giving classes. They also are suggested to vary the techniques in literary teaching so that the students will not get some boredom during the classes. They are also strongly encouraged to be able to maintain a democratic model of teaching as well as model of assessment.

\section{REFERENCES}

(2013) Literature in English: Teaching Syllabus 2013 Lower and Upper Secondary. Curriculum Planning and Development Division, Ministery of Education, Singapore

Abdullah, T, Zakaria, M.H, Ismail, F, Wan Mansor, Wan Fara A, Azis, M.A. (2007). A New Teaching Model to Teach Literature for the TESL Pre-Training Service Programme in Universiti Teknologi Malaysia (A Research). Malaysia: Jabatan Bahasa Moden Fakulti Pengurusan dan Pembangunan Sumber Manusia, Universiti Teknologi Malaysia

Buttler, I. (2006). “Integrating Language and Literature in English Studies: A Case Study of The English 100 Course at The University of North West" (A Ph.D Thesis in the Subject of English). The University of South Africa (unpublished). 
Carter, R., \& Long, M. (1991). Teaching Literature. Harlow, Essex: Longman

Carter, R., \& McRae, J. (eds). (1996). Language, Literature and the Learner. Harlow: Addison Wesley, Longman

Cross, T.B, Dennis, K., \& Isaacs, M. (1989). Towards a culturally competent system of care, volume I. Washington, D.C.: Georgetown University Child Development Center, CASSP Technical Assistance Center.

Cruz, J. H. R. (2010). The Role of Literature and Culture in English Language Teaching, Journal of Linguistica Aplicada, (7), available online:

http://relinguistica.azc.uam.mx/no00 7/no07_art09.htm

De Riverol, J. E. (1991). Literature in the Teaching of English as a Foreign Language, in Revista Alicantina de Estudios Ingleses 4, pp: 65-69.

Hismanoglu, M. (2005). Teaching English through literature, Journal of Language and Linguistics Studies, 1(1), April 2005, pp. 53-66.

Iberri-Shea, G. (2009). Using public speaking tasks in English language teaching, English Teaching Forum, 47(2), pp. 18-36.

Khatib, M., Rezaei, S., \& Derakhshan, A. (2011). Literature in EFL/ESL classroom, English Language Teaching, 4(1), March 2011, www.ccsenet.org/elt

Khatib, M., \& Hossein, A. R. (2012).

Literature and language teaching, Journal of Academic and Applied Studies, 2(6), pp. 32-38.

Lytovchenko, I. (2009). How to make upperlevel university English classes more interactive, English Teaching Forum, 47(2), pp. 24-29.

Oscarson, A. D. (2009). Self-Assessment of Writing in English as a Foreign Language. Goteborg, Sweden: ACTA Universitatis Gothenborgensis. ERIC DRS ED505960.

Maley, A. (1989a). Down from the Pedestal: Literature as Resource. In R. Carter, R. Walker \& C. Brumfit (eds), Literature and the Learner: Methodological Approaches. Modern English
Publications and the British Counsel, pp. 1-9

McKay, S. (1982). Literature in the ESL Classroom, TESOL Quarterly 16(4), December 1982, pp. 529-536.

McRae, J. (1991). Literature with a Small "l". London: Macmillan.

Meyers, C. (1986). Teaching Students to Think Critically (San Francisco: Jossey-Bass, 1986), p. 47.

Mujumdar, S. (2010). Teaching English language and literature in non-native context, Language in India: Strength for Today and Bright Hope for Tomorrow, 10, June 2010.

Savvidou, C. (2004). An integrated approach to teaching literature in the EFL classroom, The Internet TESL Journal, $X(12)$, December 2004, published in http://iteslj.org/

Short, M. (1996). Exploring the Language of Poems, Plays and Prose. London: Longman.

Short, M. H. \& Candlin, C. N. (1986). Teaching study skills for English literature. In C. J. Brumfit \& R. A. Carter (Eds.), Literature and Language Teaching (pp. 89-109). Oxford: Oxford University Press.

Thomas, G. C., Batson, C. D. \& Coke, Jay, S. (1981). Do good Samaritans discourage helpfulness?, Journal of Personality and Social Psychology, 40, pp. 194-200.

Tully, M. (2009). Mind mirror projects: A tool for integrating critical thinking into the English language classroom, English Teaching Forum, 47(1), pp. 10-17.

Wu, S. Y. (2008). Teaching the Three Little Pigs to EFL young learners in Taiwan, The Internet TESL Journal, XIV(1), January 2008

Yeasmin, N, Azad, Md. A.K, Ferdoush, J (2011). Teaching language through literature: Designing classroom activities. ASA University Review, 5(2), July-December 201, pp. 283-297

Zakian, M., Moradan, A., \& Naghibi, S. E. (2012). The Relationship of Self-, Peer-, and Teacher Assessments in the Speaking of EFL Learners. ERIC DRS 530967. 